\title{
Psychological Features of the Personality of Students
}

\section{of Different Specialties}

\author{
Natalia Tarabrina ${ }^{1}$, Elena Grabovskaya ${ }^{2}$, Alexey Tikhonov ${ }^{1} \&$ Yury Kraev $^{1}$ \\ ${ }^{1}$ Moscow Aviation Institute (National Research University), Moscow, Russian Federation \\ 2 Taurida Academy V.I. Vernadsky Crimean Federal University, Simferopol, Russian Federation \\ Correspondence: Alexey Tikhonov, Moscow Aviation Institute (National Research University), Moscow, 4, \\ Volokolamskoe Highway, 125993, Russian Federation.
}

Received: February 20, 2020

Accepted: March 17, 2020

Online Published: March 20, 2020

doi:10.5430/ijhe.v9n3p152

URL: https://doi.org/10.5430/ijhe.v9n3p152

\begin{abstract}
The objective of the article is the correspondence of individual and typological features of the student to the chosen direction, which promotes successful adaptation to study at the university and readiness for future professional activity. The aim is to reveal psychological features of personality of students: doctors, engineers, and jurists. Materials and methods are the following: 180 students of 1-3 year (17-25 years old): future doctors ( $n=80)$, jurists $(n=50)$, and engineers $(n=50)$. We studied the psychological characteristics of personality. The program «Mini-mult» of the medical diagnostic hardware and software complex «Biomysh Research» («Neurolab», Russia) was used. The statistical analysis was performed by parametric method using the Student's t-test.

The results are the following: students of different specialties have intergroup and individual differences in neurodynamic and cognitive functions. The most significant difference was found on scales $1,2,6,7$ ( $p<0.05-0.01)$. The personality pattern of students (future doctors and jurists) has a «peak», three-phase pattern, and no reliable differences between the contrasting ones. The average psychological profile of the personality of students, future engineers is «linear», all its indicators are between 45T and 55T. Such profile is found in persons referred to the concordant norm.

Conclusions are the following: students of all studied groups are characterized by high openness and desire to present themselves in a more favorable light on indicators of three evaluation scales (L, F, K). The psychological profiles of doctors and jurists are similar. Contrasting «peaks» are on scales of hysteria, paranoia and schizoidity. It testifies to constant dissatisfaction and indomitable aspiration to the set goal. Determination, flexibility of behavior with low level of anxiety, and confidence in decision making are inherent in future doctors and jurists. Engineering students are confident, satisfied with themselves and their surroundings, sociable, optimistic, and cheerful. However, their level of anxiety is higher than the level of jurists. It is recommended to create a system of organizational and pedagogical conditions for the formation and development of «western components of professional mobility» for students of various specialties.
\end{abstract}

Keywords: psychological personality traits, students, doctors, jurists, engineers

\section{Introduction}

One of the leading trends in the development of the modern educational situation, carried out against the background of fundamental changes in the socio-economic sphere of our society, is the increased attention to the formation of the human resources potential of a qualitatively new level (Zheltenkov, Fedotova \& Tikhonov, 2018; Tarabrina, Tikhonov \& Kraev, 2020).

For the successful recovery of the Russian economy from the crisis and to prevent a slowdown in its development, the government is taking a number of measures, the list of which includes tasks aimed at intensifying the growth of all production relations (Mikhailov, Fedotova, Tikhonov \& Novikov, 2018). They can be solved by improving the quality of professional training of the labor force, as well as by increasing the number of highly productive jobs (HPJ) that the country needs a lot (Tarabrina, 2015).

When announcing vacancies at the HPJ, many organizations and industries require that potential employees have the appropriate professionally important psychophysiological qualities (PIPQ) (Kraev, \& Tarabrina, 2019). Particular 
attention is paid to physical, functional, and psychological parameters of the future employees (Fedotova, Tikhonov \& Novikov, 2018). A person's professional performance, based on special knowledge, skills, and a certain set of professionally important physical and mental qualities, influences labor productivity (Prosvirina, Tikhonov \& Novikov, 2018). There is also an inverse relationship when a profession influences a person by forming completely different «psychophysiological portraits» (Fedotova, Tikhonov \& Novikov, 2018; Prosvirina, Tikhonov \& Novikov, 2018). For example, medical, jurist, or economic influence on a person is multidimensional: in some subjects it is manifested as harmoniously controlled and empathic, in others it is impulsive, emotionally unstable, and frustrative. Depending on the peculiarities of professional activity, there is a variable frequency of occurrence of different types of influence (Tarabrina, 2015).

It becomes obvious that the problems of professional selection at sufficiently stringent modern requirements acquire not only great urgency, but may also have a crucial importance for both employers and the hired specialist. The problem of professional selection with certain PIPQ arises not only for institutions and organizations that offer HPJ, but also for higher education institutions that train future specialists (Kraev, \& Tarabrina, 2019).

There is a relevance of training issues in a lot of studies (Boscan, Penn, Velasquez, Reimann, Gomez, Guzman, Berry, Infantes, Jaramillo \& Romero, 2000; Prosvirina, Tikhonov \& Novikov, 2018; Baurina, 2016). It is shown that students of engineering specialties are characterized by a focus on success and achievement of maximum results in different fields of life and the integration of its various styles. In the future, on the one hand, independence in the profession is important to them, on the other hand, a sense of job stability too (Mikhailov, Fedotova, Tikhonov \& Novikov, 2018). Future jurists experience psychological difficulties in mastering the profession and have low indicators when solving professional situations that contain a psychological factor (Tarabrina, 2015). The 21st century is marked by a very close interaction of psychology and medicine. In this regard, psychological training is becoming one of the most rapidly developing and attracting attention aspects of medical education. Studies have shown that there are significant relationships between many aspects of the interpersonal skills of clinicians, on the one hand, and the degree of satisfaction and motivation of patients, on the other. (Rattanapitoon, S, Rattanapitoon, N. \& Ueng-arporn, 2013).

Researcher M. S. Emmert and co-authors (Emmert, 2014), as well as our previous studies (Tarabrina, 2015) show that the professionally important qualities of future doctors, jurists, and engineers should include general endurance (also for most professions, because it defines the level of a specialist's work capacity and, consequently, his fatigue rate) (Tarabrina, 2016), static and dynamic force of «knowledged» muscles (back, abdominal press, and shoulder belt) (Tarabrina, 2016), dexterity of the hand muscles (Melnichenko, Tarabrina, Mishin \& Ozerova, 2008), communicative and organizational abilities, attention switching, logical thinking, operative memory, and self-governance ability (stress resistance) (Kraev \& Semina, 2017) (Figure 1). However, for a more complete characterization of the psychophysiological status of students of different specialities, it is necessary to study the psychological features of the personality.

The aim is to identify the psychological characteristics of the personality of future doctors, engineers, and jurists.

\section{Materials and Methods}

Participants: 180 students of 1-3 year $(17-25$ years old $)$ : future doctors $(n=80)$, jurists $(n=50)$, and engineers $(n=50)$ of aerospace industry $(n=50)$. We studied the psychological characteristics of personality with the program «Mini-mult» of the medical diagnostic hardware and software complex «Biomysh Research» («Neurolab», Russia) was used. It was developed by Swedish psychologist J. C. Kincannon (1968) and adapted in the Russian version by V. P. Zaitsev (1981). This is a shortened version of the Minnesota Multiphasic Personality Inventory test (MMPI), a technique for multifaceted personality research designed for rapid assessment of mental adaptation of large contingents of subjects and for dynamic self-control. It is not only used in the clinic to assess the personality structure and mental state of the subjects, but it is increasingly used in the examination of healthy people (students, athletes, etc.) to obtain additional information about personality traits and possible abnormalities (for example, identification of psychopathic traits) (Kincannon, 1968; Woodward, Goodman \& McLean, 1973; Zaitsev, 1981).

Procedure (organization of research): students were tested in classrooms before classes began. At the preliminary stage, all examiners were registered in a computer database. Then everyone was presented with a test consisting of 71 questions (statements). After the program was launched, a dialog box was opened on the screen, where students were asked to read the question and choose an appropriate answer for the examinee (Rattanapitoon, Rattanapitoon \& Ueng-arporn, 2013). The questions were followed in order. The time of examination of each subject was no more than 15 minutes. Interpretation of the results was performed on 11 scales. 3 rating scales (L, F, K) reflect the sincerity of the test subject, the credibility of the test results and the amount of correction made by excessive caution. The 
remaining 8 scales are basic, assessing personality traits. Test results are processed using a set of special tables, resulting in T-points. Indicators above $70 \mathrm{~T}$ and below 40T were assessed as deviations from the norm (Zaitsev, 1981).

Statistical analysis: survey results were statistically processed using the «STATISTICA 10.0» software package. Parametric methods were used, the reliability of the differences in the obtained results was determined using the Student's t-test at $\mathrm{p}<0.05$. The arithmetic mean $(\mathrm{M})$ was used as a measure of the central trend, and the standard error of it (m) was used as a scattering measure.

\section{Results}

As a result of the conducted research the data characterizing psychological features of students (doctors, jurists. and engineers) were obtained. It is known that the values of T-points of the main profile scales, which are within the range from 40T to 70T, are considered the norm and are called the «corridor of norm». In the sample of medical students all the scales of the main profile are within the range from $47.60 \pm 1.20 \mathrm{~T}$ to $77.13 \pm 2.00 \mathrm{~T}$, with «peaks» corresponding to scales F, 3, 6, 8 (Table 1). Such type of profile can be referred to as «peak», or more precisely as «three-phase». The leading features of such a profile are those inherent in the scales corresponding to the «peaks». The greatest value of T-points of scales of the basic profile corresponds to scale $F-77.13 \pm 2.00 \mathrm{~T}$ (Figure 1). Such a high value of the profile level indicator on $\mathrm{F}$ scale may show unreliable answers or sometimes the need for self-expression among young people with low critical thinking, uncomfortable views, and tendency to conflict behavior (Boscan, Penn, Velasquez, Reimann, Gomez, Guzman, Berry, Infantes, Jaramillo \& Romero, 2000). The values of the other T-points of the basic profile are within the upper limit of the norm. Contrasting «peaks» are marked on the scales of hysteria (Hy), paranoia ( $\mathrm{Pa})$, and schizoidity ( $\mathrm{Se}$ ).

Since the values of T-points on these scales are within the doctors are characterized by some difficulty of social adaptation, desire to pay attention to them, to stand out, without any reason, about the propensity to self-esteem, artistic expression of them. Such students are prone to non-standard approaches and ideas, sometimes far from their implementation and not quite practical (Booth Jr, 2013).

The results of the legal student survey are presented in the Table 1 and graphically interpreted in the Figure 1 . The analysis of the average psychological profile jurists has shown the same «three-phase» figure of personality as for doctors. In this case «peaks» coincide with scales of doctors and have no reliable distinctions. The values of almost all basic scales are within normal limits, but much closer to the «middle corridor».

Table 1. T-points of the basic scales of the following students: doctors $(n=80)$, jurists $(n=50)$, engineers $(n=50)$

\begin{tabular}{|c|c|c|c|c|}
\hline \multirow{2}{*}{ № } & \multirow{2}{*}{ Scale } & \multicolumn{3}{|c|}{ Indicators } \\
\hline & & doctors & jurists & engineers \\
\hline $\mathrm{L}$ & Lies & $50.62 \pm 1.40$ & $52.25 \pm 1.30$ & $48.92 \pm 1.50$ \\
\hline $\mathrm{F}$ & Reliability & $77.13 \pm 2.00$ & $72.33 \pm 3.90$ & $51.31 \pm 1.50$ \\
\hline K & Correction & $48.56 \pm 7.60$ & $52.38 \pm 7.00$ & $48.02 \pm 1.30$ \\
\hline $1(\mathrm{Hs})$ & Hypochondria & $55.03 \pm 1.70$ & $46.00 \pm 3.30$ & $54.00 \pm 1.60$ \\
\hline 2 (D) & Depression & $61.00 \pm 2.00$ & $58.00 \pm 2.70$ & $51.68 \pm 2.10$ \\
\hline 3 (Нy) & Hysteria & $64.05 \pm 2.00$ & $61.35 \pm 1.60$ & $56.78 \pm 2.00$ \\
\hline $4(\mathrm{Pd})$ & Psychopathy & $52.35 \pm 2.00$ & $46.17 \pm 2.00$ & $44.26 \pm 1.90$ \\
\hline $6(\mathrm{~Pa})$ & Paranoia & $68.98 \pm 1.10$ & $61.79 \pm 1.40$ & $51.65 \pm 2.00$ \\
\hline $7(\mathrm{Pt})$ & Psychasthenia & $47.60 \pm 1.20$ & $36.66 \pm 1.80$ & $55.92 \pm 2.00$ \\
\hline $8(\mathrm{Se})$ & Schizoidity & $63.36 \pm 2.10$ & $53.23 \pm 2.20$ & $52.71 \pm 1.60$ \\
\hline $9(\mathrm{Ma})$ & Hypomania & $61.52 \pm 1.20$ & $60.14 \pm 1.60$ & $50.18 \pm 1.70$ \\
\hline
\end{tabular}




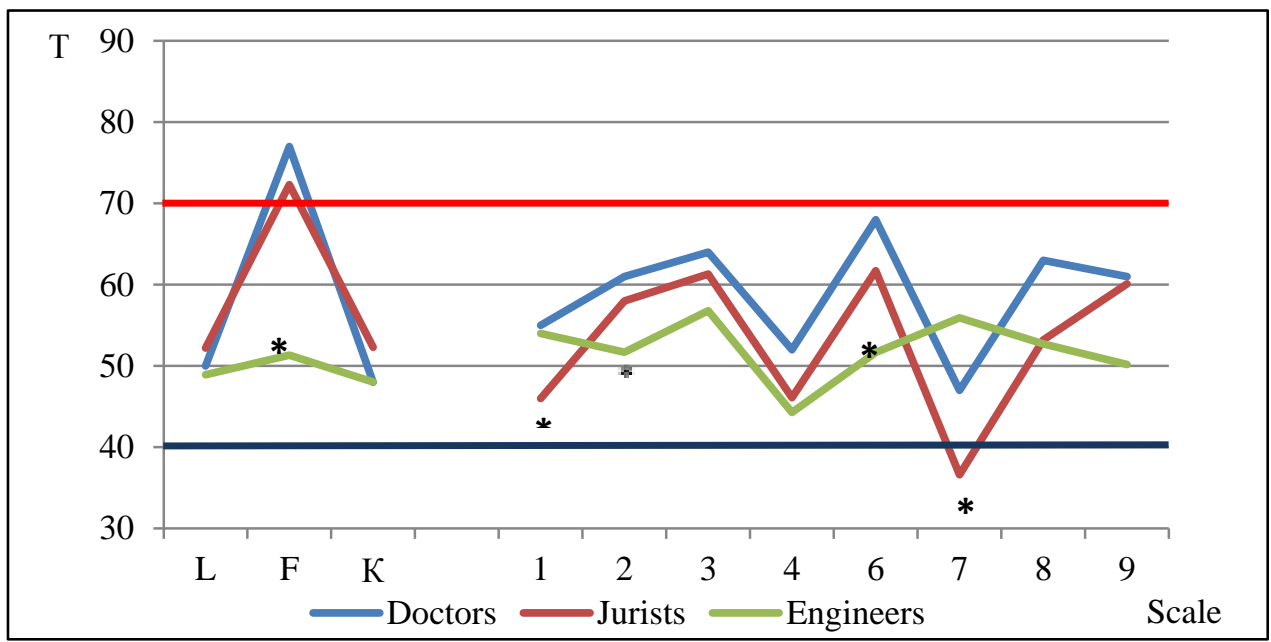

Note: $\mathrm{L}$ is the scale of lies, $\mathrm{F}$ is the scale of reliability, $\mathrm{K}$ is the scale of correction, 1 is the scale of hypochondria, is the scale of depression, 3 is the scale of isteria, 4 is the scale of psychopathy, 6 is the scale of paranoia, 7 is the scale of psychasthenia, 8 is the scale of schizoidity, 9 is the scale of hypomania.

$*-\mathrm{p}<0.05$ is the level of relevance; $* *-\mathrm{p}<0.01$ is the level of relevance Student's t-test.

Figure 1. Average psychological profile of the following students: doctors $(n=80)$, jurists $(n=50)$, engineers $(n=50)$

The exception is the psychasthenia $(\mathrm{Pt})$. T-points of this scale are extremely low: $36.66 \pm 1.80 \mathrm{~T}$. Values are $23 \%$ lower than of doctors. This probably indicates the lack of caution in actions and scrupulousness in matters of morality, rather naked self-centeredness, reduced ability to empathize, nonconformity of attitudes, rough and rigid manner of behavior, and cynical outlook on life. Such a decline on the 7th scale indicates a non-critical attitude to one's «ego» and overestimation of one's abilities, which may be the reason for the adaptation disorder.

Future jurists and doctors have the highest T-point value of the main profile scale corresponds to $\mathrm{F}$ scale: $72.33 \pm 3.90 \mathrm{~T}$. Absolute values are $7 \%$ less than of jurists. Such a moderate increase in the F scale can be associated with internal tension and dissatisfaction with the situation of students in the first years of study, adaptation to the changed situation in communication, and specifics of education (Zhumataeva, Bapaeva \& Shiganova, 2016).

The psychological profile of engineering students differs significantly from future doctors and jurists. According to the reliability scales, there is a significant difference on the F scale: for engineers it is $48.69 \%$ lower ( $p<0.01$ ) than for others. The scales of lies and corrections were within the norm and did not differ significantly. In general, average profile of engineering students can be classified as «linear», because all its indicators are between 45T and 55T. As it is shown in the Figure 1, engineering students had an inversion of depression (D) and psychasthenia (Pt) scales. Their level of anxiety (on psychasthenia scale) was $55.92 \pm 2.00 \mathrm{~T}$, which is $52.53 \%(\mathrm{p}<0.05)$ higher than for the group of jurists and it is normal.

The comparative analysis of the results obtained in all three selected groups revealed significant differences on scales $1,2,6,7$. Thus, on the base scale of hypochondria (Hs), jurists have the lowest T-points value, equal to 46.00 $\pm 3.30 \mathrm{~T}$. The value of this scale for future jurists is lower by $16 \%(\mathrm{p}<0.05)$ than for doctors and engineers. This can be explained by the specifics of medical training from doctors, and engineers have a tendency to demonstrate their accuracy, firmness, diligence, and integrity. On a base scale of depression (D), engineering students have the lowest values: $51.68 \pm 2.10 \mathrm{~T}$. Doctors and jurists have T-points higher on this scale by $12.2 \%$ and $18.0 \%$ respectively. This trend may indicate that future jurists are more resistant to depression and anxiety. For engineering students, such results indicate low levels of anxiety, activity, sociability, sense of importance, strength, energy, and vigor. At the same time, indicators for all three groups are within the «norm corridor». On the basic paranoia (Pa) scale, engineering students have the lowest values corresponding to the norm. The T-points on the paranoia scale were $33.6 \%$ $(\mathrm{p}<0.05)$ and $19.6 \%$ higher for doctors and jurists, respectively, and were approaching the upper limit of the norm. According to the basic scale of psychasthenia $(\mathrm{Pt})$, the students-engineers also had no deviations from the norm. Doctors and jurists had negative «peaks» of T-points on the scale of psychasthenia. At the same time, doctors' results are $14.9 \%$ lower. The result for jurists is lower by $34.4 \%$ and goes beyond the lower boundary of the «norm corridor». Higher values on the scale 8 (schizoidity) were also marked for doctors than for future jurists and 
engineers by $15.5 \%$ and $24 \%$ higher respectively (Table 1, Figure 1). In general, the values on all base scales for engineers and jurists are lower and closer to the norm than for doctors.

\section{Discussion}

Researches devoted to studying of psychological features of personality of students of different specialties are actual. According to some authors (Zhumataeva, Bapaeva \& Shiganova, 2016), student age is the final stage of socialization. The main task of this age is to choose a profession and a type of educational institution. This leads to a differentiation in the life path of students of different educational institutions and to a wider range of interests and responsibilities. Psychological features influence the character of an individual, his or her success and failure in a particular professional activity, and interaction with other people in professional and personal spheres (Zhumataeva, Bapaeva \& Shiganova, 2016). A rather large number of authors investigate the differences in psychological features of the personality of students of technical and artistic specialties and programmers (Klimov, 1996; Emmert, 2014; Zhumataeva, Bapaeva \& Shiganova, 2016). At the same time, the majority of domestic authors believe that the way of life and professional activity, «...which determines the personal peculiarities of subjects and their professional motivation» is the determinant in the development of personal features (Klimov, 1996). In our study, psychological features of the personality of future doctors, jurists and engineers have been studied. Based on the results of MMPI questionnaire, we studied the personality traits of students of different specialties. Thus, according to the T-points on the $\mathrm{L}$ and $\mathrm{K}$ scores, the students of all three groups are characterized by quite high openness and tendency to present themselves in a more favorable light, demonstrating strict compliance with social norms. On the F scale, future doctors and jurists have high scores, indicating low reliability of responses and possibly increased anxiety about testing. The psychological profiles of future doctors and jurists have much in common. For example, they may be better able to show themselves in situations where there is a need to quickly change their role, where there are short-term contacts and the ability to adapt to different people. Determination, flexibility of behavior with low levels of anxiety, and confidence in decision making are also inherent in them. They will help to carry out their professional activities (Zaitsev, 1981). Perhaps they are characterized by straightforwardness, sense of competition, desire to appreciate their achievements, and some disregard for established rules of conduct and customs.

The psychological profile of engineering students is slightly different. They are characterized by low levels of anxiety, activity, sociability, sense of their importance, strength, energy, and vigor. One of the psychological traits is the tendency to maintain constant interests, attitudes, determination, flexibility of behavior with low levels of anxiety, and confidence in decision-making. This psychological picture is quite consistent with the profile of students of technical specialties. In the professional activity of an engineer such qualities are rather important. The data obtained agree with the results of our previous studies, as well as with the opinion of a lot of authors (Tarabrina, 2015; Gordienko \& Silaeva, 2015). Thus, A. B. Baurina believes that future engineers are characterized by the following: low anxiety, emotional comfort, acceptance of oneself, adaptability, low level of emotionality, and rational behavior under stress (Baurina, 2016). Thus, the conducted researches testify to the presence of features in the psychological profile of future doctors, jurists, and engineers. The success and failure in a particular professional activity, style of interpersonal communication, and interaction with other people in the professional and personal spheres largely depend on these features (Zhumataeva, Bapaeva \& Shiganova, 2016).

\section{Conclusion}

On the indicators of three rating scales (L, F, K) students of all study groups are characterized by high openness and desire to present themselves in a more favorable light. Psychological profiles of future doctors and jurists have similar character. Contrasting «peaks» are marked on scales of hysteria, paranoia, and schizoidity. This testifies to constant dissatisfaction and indomitable aspiration to the set goal. Determination, flexibility of behavior with low level of anxiety, and confidence in decision making are inherent in future doctors and jurists. Engineers are confident, satisfied with themselves and their surroundings, sociable, optimistic, and cheerful. However, their level of anxiety is higher than of jurists. It is recommended to create a system of organizational and pedagogical conditions for the formation and development of «western components of professional mobility» for students of various specialties.

Further research is supposed to be carried out in the direction of studying the psychological characteristics of the personality of students in different career paths, such as students studying business, agriculture, psychology, or education.

\section{References}

Baurina, A.B. (2016). Differences in psychological make-up of students of technical and artistic specialties. Bulletin of Moscow state regional University. Series: Psychological Sciences, 4, 114-122. 
https://doi.org/10.18384/2310-7235-2016-4-114-122

Booth Jr, E. G. (2013). Personality Traits of Athletes as Measured by the MMPI. Research Quarterly. American Association for Health. Physical Education and Recreation, 29, 127-138. https://doi.org/10.1080/10671188.1958.10612974

Boscan, D., Penn, N., Velasquez, J., Reimann, J., Gomez, N., Guzman, M., Berry, E., Infantes, L., Jaramillo, L. \& Romero, M. (2000). MMPI-2 profiles of Colombian, Mexican, and Venezuelan university students. Psychological reports, 87, 107-110. https://doi.org/10.2466/PR0.87.5.107-110

Emmert, M.S. (2014). Assessment of efficiency of development of professionally significant qualities of future specialists in personnel management. Omsk Scientific Bulletin, 5(132), 177-178.

Fedotova, M.A., Tikhonov, A.I. \& Novikov, S.V. (2018). Estimating the effectiveness of personnel management at aviation enterprises. Russian Engineering Research, 38(6), 466-468. https://doi.org/10.3103/S1068798X18060084

Gordienko, N. \& Silaeva, K. (2015). Psychological and Psychophysiological Research of the Attitude System of Students for Technical and Humanitarian Specialties. Revista Romaneasca pentru Educatie Multidimensionala, 219-231. https://doi.org/10.18662/rrem/2015.0701.16

Kincannon, J.C. (1968). Prediction of the standard MMPI scale scores from 71 items: the mini-mult. J Consult Clin Psychol, 32(3), 319-325. https://doi.org/10.1037/h0025891

Klimov, E.A. (1996). Psychology of professional self-determination. Rostov-on-Don: Phoenix.

Kraev, Yu.V. \& Semina, A.P. (2017). An overview of the types of aggression in human resources. Moscow economic journal, 4, 70.

Kraev, Yu.V. \& Tarabrina, N.Yu. (2019). Comparative analysis of the features of the manifestation of stress in physical education teachers and students. Moscow Economic Journal, 1, 63.

Melnichenko, E.V., Tarabrina, N.Yu. \& Parkhomenko, A.I. (2010). Myovisceral reflex correction of vestibular reactions of the cardiovascular system in athletes. Tauride Medical and Biological Bulletin, 13(3), 133.

Melnichenko, E.V., Tarabrina, N.Yu., Mishin, N.P. \& Ozerova, L.A. (2008). Correction of motor qualities in the conditions of vestibular loads by the method of active traction-rotational muscle relaxation. Scientific notes of Taurida national University named after V. I. Vernadsky. Series: Biology, chemistry, 21(3), 88-92.

Mikhailov, A.A., Fedotova, M.A., Tikhonov, A.I. \& Novikov, S.V. (2018). Problems of professional self-determination of students. Financial economics, 6, 206-210.

Prosvirina, N.V., Tikhonov, A.I. \& Novikov, S.V. (2018). Education of students in the context of cultural development. Moscow Economic Journal, 3, 19.

Rattanapitoon, S., Rattanapitoon, N. \& Ueng-arporn, N. (2013). Medical Students Personality using Minnesota Multiphasic Personality Inventory (MMPI) Psychological Test. Conference: International Conference on Molecular Biology and Biomedicine, Tokyo, Japan.

Tarabrina, N.Yu. (2015). Psychophysiological assessment of the health of law students. Theory and practice of physical culture, 1, 52-54.

Tarabrina, N.Yu. (2016). Muscle relaxation in the system of correction of scoliotic changes in the cervical-thoracic spine of athletes. Theory and practice of physical culture, 4, 30-32.

Tarabrina, N.Yu., Tikhonov, A.I. \& Kraev, Yu.V. (2020). Professional-applied physical training of future HR specialists. Espacios, 41, 6-7.

Woodward, C., Goodman, J. \& McLean, A. (1973). Comparisons of the MMPI and Mini-Mult. Canadian Journal of Behavioural Science. Canadian Journal of Behavioural Science, 5, 76-82. https://doi.org/10.1037/h0082331

Zaitsev, V.P. (1981). Version of the psychological test MIPI-M. Psychological journal;3, 118-123.

Zheltenkov, A.V., Fedotova, M.A. \& Tikhonov, A.I. (2018). Analysis of the quality of professional training of personnel management specialists in higher educational institutions. Bulletin of the Moscow State Regional University, 2, 61-70. https://doi.org/10.18384/2310-6646-2018-2-61-70

Zhumataeva, M.S., Bapaeva, M.K. \& Shiganova, K.U. (2016). Psychological and psychophysiological features of students. Modern Innovations, 5(7), 76-78. 